\title{
Synthesis and Characterisation of Styrene Butadiene Styrene Based Grafted Copolymers for Use in Potential Biomedical Applications
}

\author{
James E. Kennedy and Clement L. Higginbotham \\ Department of Polymer Engineering, \\ Athlone Institute of Technology, Dublin Rd, Athlone, Co. Westmeath, \\ Ireland
}

\section{Introduction}

In the annals of history the evolution of the synthetic rubber industry can be traced to the early 1930s where the first emulsion polymerised styrene butadiene rubber known as Buna $S$ was prepared by I. G. Farbenindustrie in Germany. But it was not until the US Government in 1940 established the Rubber Reserve Company, a stockpile of natural rubber and the development of a synthetic rubber program came into full fruition. However, when the United States entered World War II, the synthetic rubber plants owned by the US Government were either closed or sold to private industry between the years 1946 and 1955, and from this the development of this formidable technology began. In the early 1960's one primary objective prevailed and that was the economical polymerisation of polyisoprene with a high cis-1,4 structure, which is the synthetic version of natural rubber(Holden \& Hansen, 2004). Around this time, workers at Shell investigated lithium metal initiators for isoprene polymerisation and found that alkyllithiums yielded some interesting results. In particular, there was no chain termination or chain transfer steps present. Thus, when all of the original monomer was consumed, the polymer chain still remained active and could initiate further polymerisation if more monomer, either of the same or different species, were added (Holden \& Hansen, 2004). Parallel with these developments, tri-block copolymers using difunctional initiators were also reported in the literature (Szwarc et al., 1956; Szwarc, 1956). These block copolymers were produced under conditions that gave polydiene segments a relatively low 1,4 content(Holden \& Hansen, 2002). However, poor elastomeric properties were acknowledged whereby the rheological properties of both polybutadiene (PB)(Gruver, 1964) and isoprene(Holden, 1965) resulted in the materials exhibiting Newtonian behaviour and the viscosities of the pure polymers approach constant values as the shear rate approaches zero. This behaviour resulted in bales of these elastomers appearing to be solid but in fact behaved as viscous liquids which hindered both their storage and commercial attractiveness. In light of this, Shell chemical research polymerised polydiene elastomers with various molecular weights to combat this problem (Holden \& Hansen, 2004). Later studies included work on block copolymers resulting in the formation of a material which contained short blocks of polystyrene on either end of the elastomeric chain to form a styrene butadiene styrene (SBS), as illustrated in Figure 1. In contrast to the diene homopolymer, these block copolymers demonstrated, non-Newtonian 
behaviour, high tensile strength, high elongation and rapid and almost complete recovery after elongation (Holden \& Hansen, 2004; Holden, 1962)

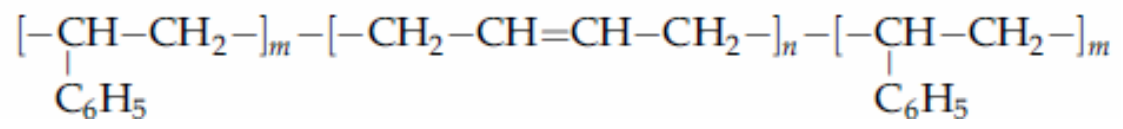

Fig. 1. Structure of a styrene-butadiene-styrene block copolymer.

Depending on the overall butadiene content, SBS block copolymers can either be used as thermoplastic elastomers (Holden \& Kricheldorf, 2004) or as blend components enhancing the mechanical performance of transparent polystyrene (PS)-based plastics (Knoll \& Niessner, 1998) and (Wagner, 2004). A very similar behaviour is also found for styreneisoprene (SI) block copolymers. Due to their compatibility with PS and the wide range of possible mechanical properties, these two materials dominate the market for block copolymers in plastics even over 40 years after their discovery (Nestle et al.,2007).

\section{Phase separation of SBR and SBS copolymers}

One of the most important properties of a SBS structure is the phase separated system, where the two phases (polystyrene and polybutadiene) retain many of the properties of their respective homopolymers. For example, tri-block copolymers have two glass transition temperatures $\left(\mathrm{T}_{\mathrm{g}}\right)$ which are characteristic of the respective homopolymer (Polystyrene $\sim 100^{\circ} \mathrm{C}$ and Polybutadiene $\sim-90^{\circ} \mathrm{C}$ ) whereas styrene butadiene rubber copolymers have a single intermediate $\mathrm{T}_{\mathrm{g}}$. Regarding the aforementioned material, experimentally a single glass transition can be found at about $-65^{\circ} \mathrm{C}$ which is in accordance with a material with a styrene content of 23\% (Van der Vegt, 2005). A graphic illustrating the glass rubbery transition of the two aforementioned copolymers is presented in Figure 2. Thus, at room temperature the polystyrene phase is strong and rigid where as the polybutadiene phase is soft and elastomeric.

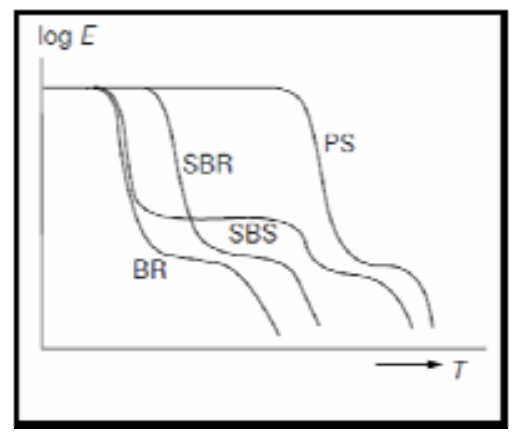

Fig. 2. The glass-rubber transitions for styrene and butadiene copolymer systems (Van der Vegt, 2005).

If the polystyrene phase is only a minor part of the total volume, it is then reasonable to postulate a phase structure as illustrated in Figure 3. From this structure, the polystyrene phase consists of separate spherical regions known as domains. Since both ends of each polybutadiene chain are terminated by polystyrene segments, these rigid domains act as 
multifunctional junction points to give a crosslinked elastomer network similar in many respects to that of a conventional vulcanised rubber (Brydson, 1978). Thus, when SBS is heated, the domains soften and the network loses its strength resulting in the ability of the block copolymer to flow which is one of the main characteristics associated with these types of thermoplastic elastomers. When the heated block copolymer is cooled, the domains become hard and the original properties are regained.

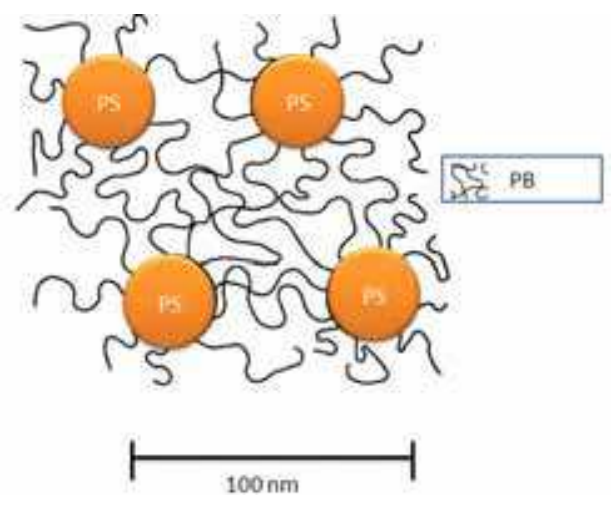

Fig. 3. Phase structure of SBS.

Therefore, when one or more blocks are capable of crystallising, additional transitions (corresponding to the $\mathrm{T}_{\mathrm{m}} \mathrm{s}$ of the blocks) will be observed whilst both the morphology and solution properties will be more complicated (Brydson, 1978).

\section{Morphology evaluation of SBS}

Three types of microphase segregation can occur within SBS systems in which one or another of the components are either in spheres, rods (cylinders) or lamellae where the morphology depends on the concentrations of styrene or butadiene used. In an ideal situation the greatest interest is in a system by which the polystyrene segments are concentrated into spherical domains. If, however, a system was produced in which one of the components exists in cylindrical or rod like domains uniformly oriented in a single direction, or the two components were arranged in lamellae, then it should be possible to obtain rubbers which demonstrate anisotropic mechanical properties (Brydson, 1978). According to Adhikari et al.,(2003), when investigating the deformation behaviour of styrene butadiene star block copolymer/hPS blends, the microphase separated blends with PS particles in lamellar matrix exhibited debonding at the particle-matrix interface. Therefore, the morphology formation in block copolymers is influenced by a number of factors: these include monomer types, chemical composition and even the processing history. Burford et al., (2003) found that interpenetrating networks (IPNs) made by the polymerisation/crosslinking of styrene in the dispersed styrene rich phase of a block copolymer within a crosslinked elastomeric matrix formed networks which combined stiffness and toughness. This formation of IPNs can allow the production of materials with controlled morphologies and the greater probability of synergistic property enhancement. But the morphologies of these IPNs are generally complex because they show varying degree of phase separation, with phases varying in size, shape and definition at interfaces. Adhikari and co-workers (2004) have researched into the deformation behaviour of 
styrene/butadiene block copolymers with a polystyrene content of $\sim 70 \%$. They noted that the phase separation behaviour of the copolymers was found to be strongly affected by asymmetric molecular architecture. It has been demonstrated that the phase behaviour of a binary block copolymer/homopolymer mixture is primarily governed by the length of the homopolymer chains relative to the corresponding block of the block copolymer (i.e. the ratio $\mathrm{N}_{\text {homo-A }} / \mathrm{N}_{\text {block-A}}$, where $\mathrm{N}_{\text {homo-A }}$ and $\mathrm{N}_{\text {block-A }}$ represent the degree of polymerisation of added homopolymer $\mathrm{A}$ and corresponding block $\mathrm{A}$ in the block copolymer $\mathrm{AB}$ respectively). Thus, there is competition between microphase and macrophase separation in a binary block copolymer/homopolymer blend composition. In such blends, according to Adhikari et al.,(2004) low molecular weight homopolymer is solubilised within the corresponding block of the copolymer at low concentration. As the molecular weight of homopolymer approaches that of the corresponding molecular weight of PS or PB in the copolymer, it tends to segregate to the middle of the microdomains. However, if the molecular weight of the homopolymer is larger than that of the corresponding block of the block copolymer, macrophase separation tends to predominate.

\section{Microphase separation of SBS copolymer}

Microstructures occur when SBS copolymers undergo microphase separation due to the thermodynamic incompatibility of PS and PB blocks. This separation is a result of the miscibility gap of polybutadiene and polystyrene in the solid-state and is crucial for the properties of the material. Since both the chain architecture of the block copolymer and the microphase separation affect the mobility of the butadiene-rich phase (Nestle et al., 2007). These elements, rich in one block, take the form of either spherical, cylindrical or lamellar domains (as previously discussed) dispersed in a continuous matrix of the other component. The phase-separated structure for SBS contains two homogeneous, nearly pure phases and a third diffuse interphase (Spaans et al., 1999). A schematic of these phases is illustrated in Figure 4 .

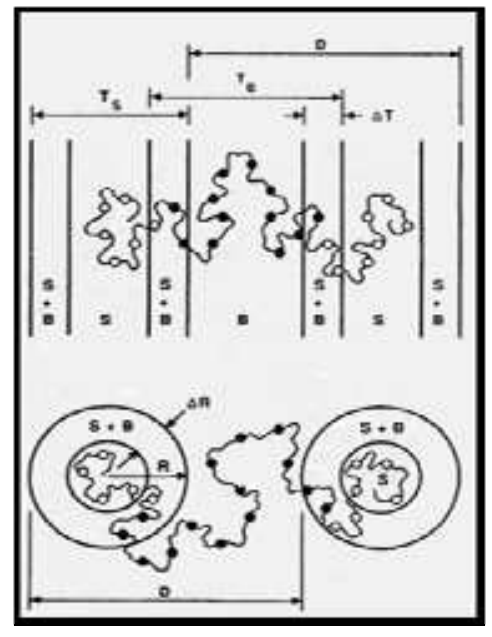

Fig. 4. Schematic representation of SBS molecule embedded in a phase separated microstructure consisting of matrix $B$, core $S$ and a broad interphase of mixed $S$ and B. $S$ represents styrene and B represents butadiene (Spaans et al., 1999). 
Spaans et al., (1999) has correlated this information with a typical DSC thermograph of SBS to represent the locations of these microphase domains. A graphical representation illustrating Spaans concept is shown in Figure 5.

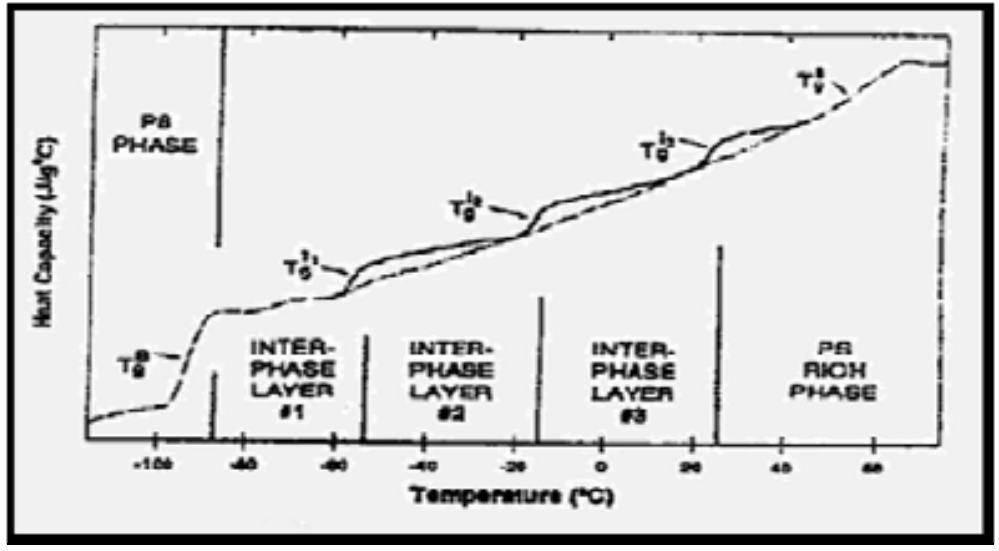

Fig. 5. A graphical representation of a DSC thermograph illustrating the Tg changes in the local heat capacity at a sequence of positions through the interfacial region, as the sample experiences a broad temperature range (Spaans et al., 1999).

\section{Thermal properties of a SBS copolymer}

Based on experimental data carried out by the authors, a linear tri-block SBS with $69 \%$ butadiene content under the trade name Kraton D1101 (see Table 1) was investigated. As presented in Figure 6, a $\mathrm{T}_{\mathrm{g}}$ value at $-92^{\circ} \mathrm{C}$ was located in the butadiene rich microphase domain which coincides with the $\mathrm{T}_{\mathrm{g}}\left(-90^{\circ} \mathrm{C}\right)$ of pure $\mathrm{PB}$ and this result is in agreement with the findings of Spaans et al.,(1999) and Kennedy et al., (2009). The glass transition of the PS domain in SBS copolymer can be detected at around $67^{\circ} \mathrm{C}$ which corresponds with the findings of Spaans et al.,(1999) , Kennedy et al., (2009) and Mohammady et al.,(2005). This value was significantly lower than the $T_{g}$ at $100^{\circ} \mathrm{C}$ for a PS homopolymer of comparable molecular weight.

\begin{tabular}{|c|c|}
\hline Butadiene/styrene ratio (wt $\%)$ & $69 / 31$ \\
\hline Total molecular weight & $102,000 \mathrm{~g} / \mathrm{mol}$ \\
\hline \multicolumn{2}{|c|}{ Microstructure of PB } \\
\hline 1,4-trans (\%) & 42 \\
\hline 1,4-cis (\%) & 49 \\
\hline $1,2(\%)$ & 9 \\
\hline
\end{tabular}

Table 1. Physical properties of Kraton D1101

The glass transition for the PS phase in thermoplastic elastomer block copolymer tends to be lower than that of pure homopolymer of the same chemical structure which is due to the 
entrapment of some centre block rubbery segments, a kinetic effect which is not thermodynamically favoured (Spaans \&Williams, 1995; Escobar et al., 2003). This lowering effect is a consequence of premature molecular motions in the PS domain induced by PB segmental mobility. Munteanu and Vasile (2005) have stated that copolymers with microphase separated morphology can be considered as finite confined systems. This confinement applied by the PB matrix to the PS discrete phase may decrease the $\mathrm{T}_{\mathrm{g}}$ of PS in SBS. According to Muhammady et al., (2001) the interfacial interaction and miscible fraction at the domain boundaries also lowers the value of the glass transition. Between $\mathrm{T}_{\mathrm{g}}$ values of PB and PS a broad continuous curvature is evident on the DSC thermograph shown in Figure 6 . This curvature should be found in all block copolymers which have homogeneous microphases present, as stated by Spaans et al., (1999). At $241^{\circ} \mathrm{C}$ a thermal transition occurs for SBS block copolymer which is believed to be a first order phase transition and corresponds to findings in literature (Spaans et al., 1999; Kennedy et al., 2009). At this transition the polymer merges into segmental homogeneity resulting in a disorganised/homogeneous state. It has been well established that when block copolymers such as SBS are heated above the upper glass transition temperature, the microstructure of the polymer will be eventually destroyed and the block copolymer will form a homogenous phase. The critical temperature at which this occurs is called an order-disorder transition (ODT) temperature (Spaans et al., 1999; Kennedy et al., 2009; Spaans \& Williams, 1995).

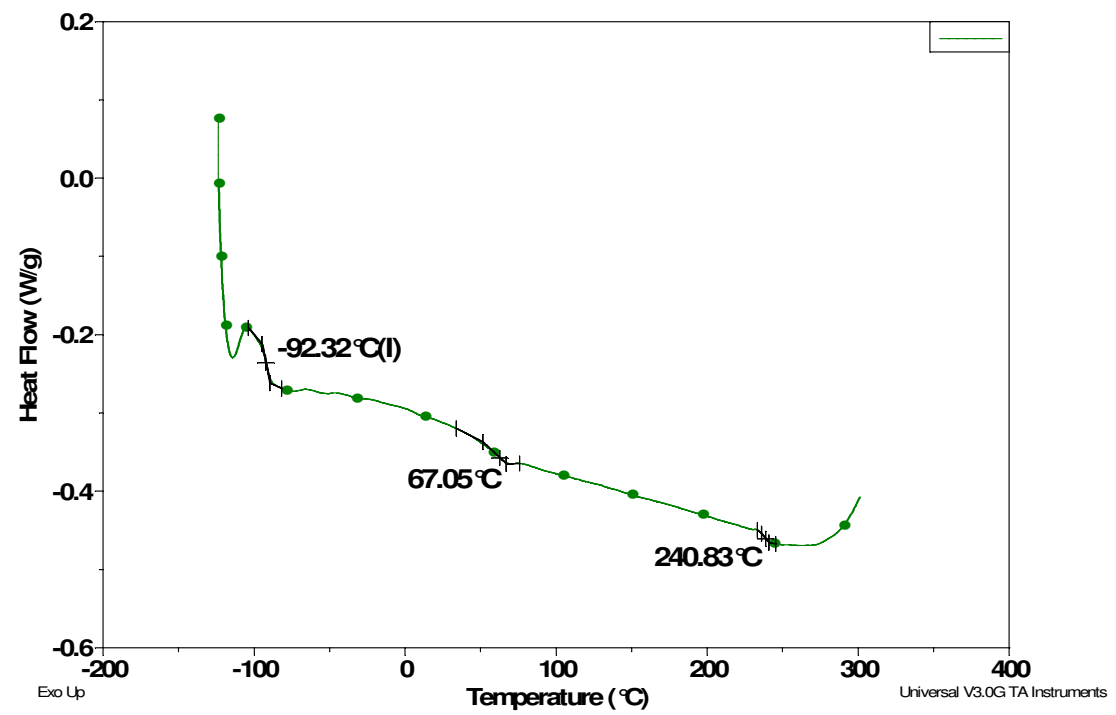

Fig. 6. A DSC thermograph of a SBS copolymer (Kraton D1101), where the $\mathrm{T}_{\mathrm{g}}$ values for PB and $P S$ are $-92^{\circ} \mathrm{C}$ and $67^{\circ} \mathrm{C}$ respectively. The separation temperature, $T_{s}$ is $241^{\circ} \mathrm{C}$.

\section{A review of Styrenic graft copolymerisation}

Huang and Sundberg (1995a, 1995b, 1995c, 1995d), have published a number of studies on the graft copolymerisation of styrene, benzyl acrylate and benzyl methacrylate onto a cis- 
polybutadiene. In their kinetic study, they have shown by the use of different initiators two possible mechanisms occurred where initiators such as benzoyl peroxide (BPO) can abstract allylic hydrogen atoms from polybutadiene while azobisisobutyronitrile (AIBN) cannot extract the allylic hydrogen atom. According to Jiang and Wilkie (1998) neither initiator appears to have significant reactivity towards addition of primary radicals to the double bond of the polybutadiene and the allylic radicals which are generated by hydrogen abstraction can initiate polymerisation of reactive monomers such as styrene and methacrylates leading to the formation of graft copolymers. Graft copolymerisation will still occur for monomers which are initiated by the allylic backbone radicals. This process occurs by addition of the growing polymeric radical to the polybutadiene double bond, producing a saturated alkyl radical which is capable of further initiation of low reactivity monomers. De Sarkar et al.,(1999) found that 1,2 -vinyl double bonds of butadiene occur in a pendant position along the polymer chain making bonds more accessible for grafting. They also postulated that the order of reactivity for vinyl groups are, $(i)$ saturation of 1,2-vinyl bonds is easier than 1,4-trans and (ii) PB is directly proportional to the amount of 1,2-vinyl bonds ( De Sarkar et al., 1999). The various structural sequences associated with butadiene are illustrated in Figure 7.

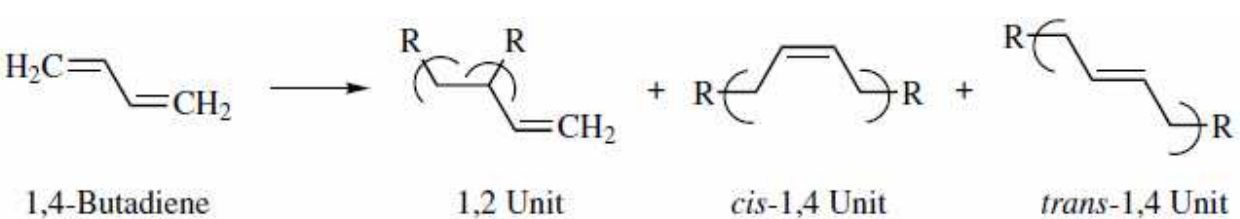

Fig. 7. Various structural formations associated with butadiene.

In the research performed by Madhusudhan and Raghunath (1999), maleic anhydride (MAH) was grafted onto ABS by the addition to the double bond initiated by BPO. Sheng and co-workers (1990) found that BPO initiated the removal of an allylic hydrogen atom while AIBN acted upon the addition of the double bond of SBR which is in agreement with the findings of Huang and Sundberg(1995a, 1995b, 1995c, 1995d). Mrrov and Velichksva (1993) described how MAH was grafted onto SIS only by the removal of an allylic hydrogen atom, whereas Zhang and Li (2003) have investigated the grafting mechanism of SBS with $\mathrm{MAH}$ using BPO and AIBN. They found that the variation of $\mathrm{C}=\mathrm{C}$ content in SBS-g-MAH was used to verify the different graft mechanisms of BPO and AIBN. They concluded that the grafting reaction occurs by the addition onto $C=C$ bond when $A I B N$ was used, while the removal of an allylic hydrogen atom was evident when BPO was used to initiate the reaction.

\section{Grafted copolymers with potential medical application}

The latest wave of biomedical materials can strengthen the capabilities of many of today's medical products. Some polymeric materials demonstrate properties such as lubricity, biocompatibility and antimicrobial action on device surfaces while others may crack, tear, slip and flake off medical devices due to inherent design flaws. There has been considerable 
interest and activity in the application of synthetic polymers in medicine, particularly for surgical and dental implants. The most critical property of a polymeric material is that it has acceptable tissue compatibility. If this criterion is not met, local tissue irritation may result. In general, the chemical structure, electric charge, hydrophilicity and hydrophobilicity, surface roughness, micro-heterogeneity, and flexibility of the materials affect the performance of cells and tissues on the materials (Minoura,1993; Yang \& Tsai, 2010). Biocompatibility can be characterised by a whole series of negatives, for example that the material was non-toxic, non-irritant, non-thrombogenic, non-carcinogenic and so on. Such a state of compatibility was most likely to be achieved by a material being inert and unrecognisable by the tissue. A desirable property of a synthetic polymeric material used in biomedical applications is that it has acceptable tissue compatibility. If this criterion is not met, local tissue irritation may result. One particular method used to obtain these desired properties is grafting hydrophilic compounds namely a hydrogel onto hydrophobic backbones. Hydrogels have physical properties similar to those of human tissue and possess excellent tissue compatibility and are used as biomedical materials. The main disadvantages of hydrogels are their poor mechanical properties after swelling. To overcome this problem, Yang \& Hsiue (1996) grafted hydroxyethyl methacrylate (HEMA) onto SBS via UV radiation. The mechanical properties of SBS-g-HEMA were found to be superior to those of poly(HEMA) and were identical to those of SBS. From their measurements, the contact angle and blood clotting time, the wetting and non-thrombogenic properties of SBS-g-HEMA were better than those of SBS. Yang et al., (1997) have also researched into the graft copolymerisation of dimethyl amino ethyl methacrylate (DMAEMA) with SBS and it was found that the degree of grafting was related to the irradiation time, DMAEMA concentration and temperature, but the adsorption of albumin and fibrinogen decreased with an increase in the amount of grafting. They continued on their work by the substitution of amino groups on the SBS-g-DMAEMA graft copolymer membrane which was treated with heparin to prepare the heparin containing SBS-g-DMAEMA (SBS-g-DMAEMA-HEP). It was found that, with increased grafting and heparin content, the surface tension and the water content of the SBS-gDMAEMA membrane increased whereas the contact angle decreased (Yang et al., 1998). Over the past few years, N-isopropylacrylamide (NIPAAm) has appeared in the literature with increasing frequency (Durne et al., 2005; Zhang et al., 2005; Geever et al., 2008; Geever et al., 2007; Geever et al., 2006; kennedy et al., 2009). Lee and Chen (2001) have grafted Nisopropylacrylamide (NIPAAm) onto SBS via solution polymerisation using benzoyl peroxide as the initiator. This was carried out to improve the water absorption and thermo sensitivity of SBS. Thus, a biomedical material often needs to function dependably without significantly altering the physical or mechanical properties of the substrate. Kennedy et al.,(2009, 2010) have successfully grafted SBS with acrylic acid (AA) and SBS with $\mathrm{N}$ - isopropylacrylamide(NIPAAm) respectively via UV polymerisation techniques for use as a potential biomedical material and in doing so; they proved that the glass transition values for each of the grafted copolymers increased in the butadiene domain, thus proving that grafting had occurred.

\section{Synthesis of graft copolymers of SBS via UV polymerisation}

UV polymerisation has become a well established technology which has found a large number of industrial applications due to the relative ease in which the reaction occurs. In 
general, a liquid resin containing a photoinitiator (Benzophenone (BP)), is transformed into a solid polymer simply by exposure to UV light (Xiang et al., 2001; Murata et al., 2004; Rohr et al., 2003; Kim et al., 2002). In order to ascertain a possible reaction site of the base polymer, Mateo et al.,(2000) investigated the photoreactions of model compounds of SBS structures 1-heptene, 3-heptenes and cumene. They concluded that the main photoreaction induced by BP in heptene derivatives, models of the cis, trans and vinyl-double bonds of the polybutadiene sequences, is the abstraction of an allylic hydrogen atom by the BP, and that, in minor extension of other hydrogen atoms of the heptene aliphatic chain. In developing grafted systems it was considered by the authors that the allylic hydrogen associated with butadiene in SBS copolymers reacted with the hydrogel monomers using benzophenone via UV polymerisation, as illustrated in Figures 7 and 8 respectively.<smiles>CCCCCCCC(C)CCC=CCCC(CC)CCC</smiles><smiles>C=CC(=O)NC(C)C</smiles>
n-isopropylacrylamide

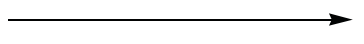

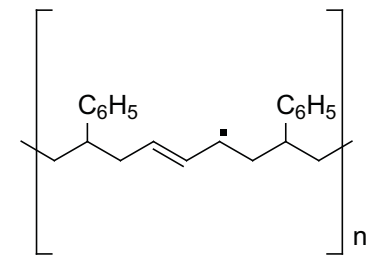<smiles>C=CC(=O)NC(C)C</smiles>
n-isopropylacrylamide

etc.<smiles>[R][N]C(C)C(C)C=O</smiles>

Fig. 7. A scheme showing the reaction of SBS and NIPAAm to yield SBS-g-NIPAAm copolymers (Kennedy et al.,2010). 
<smiles>CCC(C)CCC=CCC(CC)CC</smiles><smiles>C=CN1CCCC1=O</smiles>
n-vinylpyrrolidinone
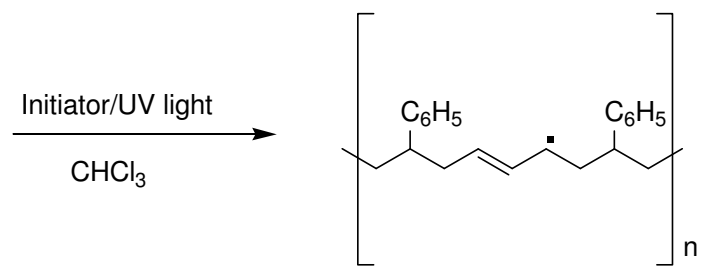<smiles>C=CN1CCCC1=O</smiles>

n-vinylpyrrolidinone

etc.<smiles>O=C1CCCN1</smiles>

Fig. 8. A proposed scheme illustrating the reaction of SBS and NVP to yield SBS-g-NVP copolymers using Benzophenone as the initiator (Kennedy \& Higginbotham, 2010)

\section{Thermal-mechanical analysis of the grafted SBS copolymers}

To appreciate the importance of these materials for biomedical use, one needs to understand the thermal properties associated with the grafted copolymers. From experimental data (Kennedy et al., 2010) the authors present DSC thermographs showing several concentrations of SBS-g-NIPAAm copolymers (Figure 9). As depicted by the DSC thermographs, exothermic variability existed in the temperature region between 50 and $200^{\circ} \mathrm{C}$ for each of the grafted copolymers. This variability was the result of both the breakdown of crosslink's which were formed within the SBS copolymer during UV polymerisation and the polymerisation of the monomers to form homopolymers. It was 
found, by exposing SBS to concentrated UV light, crosslinking takes place which has an effect on the flexibility of the material. When analysing the butadiene domain, all of the grafted samples have a broad thermal transition when compared to the PB domain of SBS. According to Rohr et al.,(2003) graft copolymerisation can also occur between the homopolymers, thus creating branched or crosslinked architectures. However, within the PB domains, the grafted copolymers that contained higher concentrations $(3,3.5$ and $4 \mathrm{~mL})$ of monomer followed the same thermal profile as that of SBS. This behaviour suggests that the pure monomer reacted more readily with itself forming a homopolymer, thus reducing the amount of grafting taking place, thus, increasing the variability within the system. The grafted copolymers which contain monomer concentrations below $2.5 \mathrm{~mL}$ have broader DSC thermographs within the butadiene rich domain resulting in $\mathrm{T}_{\mathrm{g}}$ values of the grafted samples being shifted up wards in the sub ambient domain, suggesting that grafting had occurred within this region, which coincides with the reaction sequences as presented in Figure 7. Similar observations were also found when SBS was grafted onto NVP via DSC analysis.

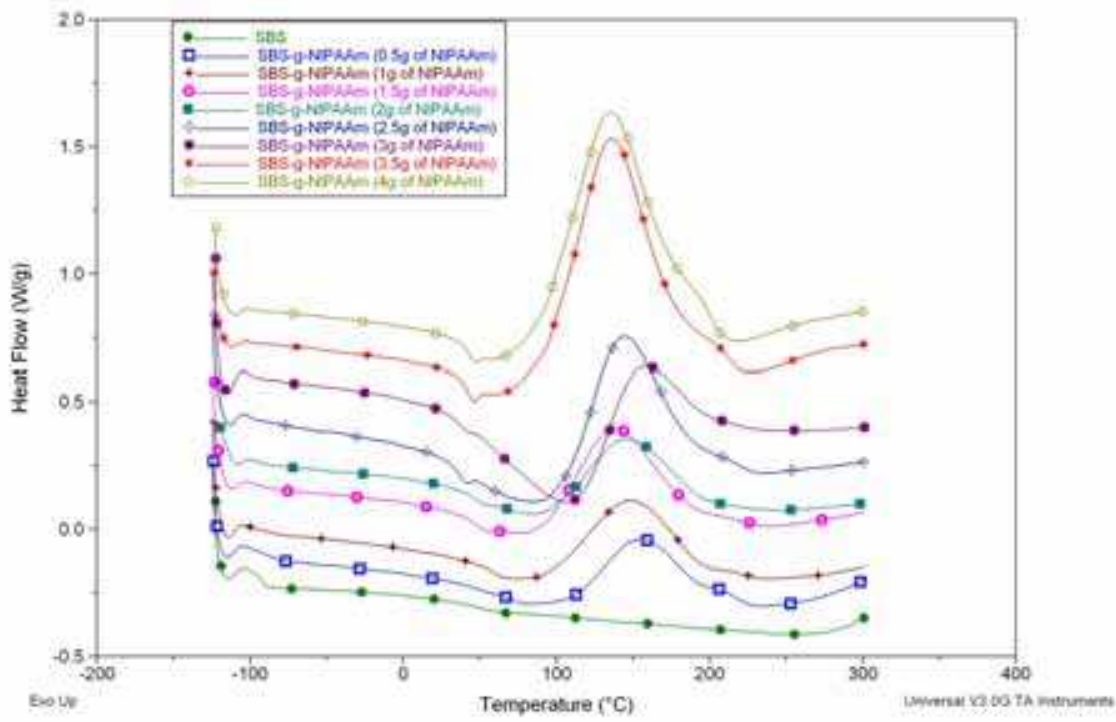

Fig. 9. DSC thermographs of SBS-g-NIPAAm resulting from the reaction of SBS and various concentrations $(0.5,1.0,1.5,2.0,2.5,3.0,3.5$ and $4.0 \mathrm{~g})$ of NIPAAm.

From DSC analysis it can be speculated that grafting took place for each of the samples tested. However, to further verify the presence of grafting, Dynamic Mechanical Thermal Analysis (DMTA) studies can be utilised (Kennedy et al., 2010). In each of the loss tangent thermograms, illustrated in Figure 10, the peak height of the tan $\delta$ value corresponds to the glass transition $\left(\mathrm{T}_{\mathrm{g}}\right)$ of the samples being tested. From thermogram shown in Figure 10, a tan $\delta$ value for SBS can be detected at $-92^{\circ} \mathrm{C}$ which is associated with the polybutadiene segment. However, there was an increase in $\tan \delta$ from $-92^{\circ} \mathrm{C}$ to $-79^{\circ} \mathrm{C}$ for non-washed SBSg-NIPAAm copolymer, indicated that grafting had occurred. This reduction in the $\tan \delta$ is an indication that the backbone of the SBS copolymer has lost some of its flexibility, due to 
the grafting of a hydrogel to its backbone. To back up this claim, the samples were washed in chloroform under soxhlet extraction for eight days and the tan $\delta$ value shifted to $-74^{\circ} \mathrm{C}$. Therefore, it is evident that the $\tan \delta$ values for each of the samples tested increased, establishing that grafting had occurred onto various butadiene segments along the SBS backbone. Thus, suggesting that grafting will increase the $T_{g}$ of the PB phase by increasing the thermal energy required to free polymer molecules from additional constraints.

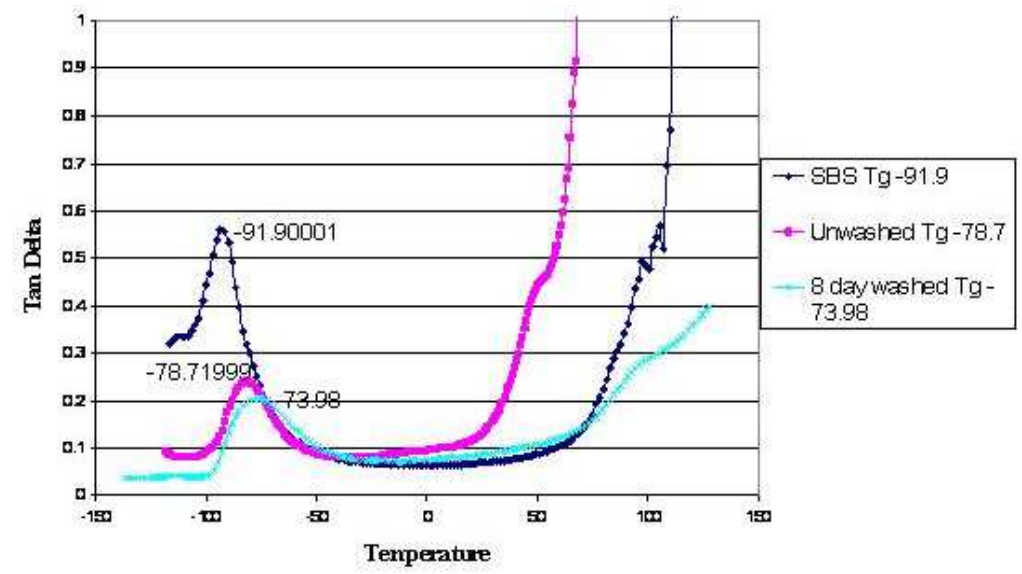

Fig. 10. DMTA spectra representing SBS, non-washed SBS-g-NIPAAm and washed SBS-g-NIPAAm samples after 8 days.

\section{Spectral analysis of the grafted SBS copolymers}

Infrared spectroscopy has been a valuable technique for materials analysis in the laboratory for over seventy years. An infrared spectrum represents a fingerprint of a sample with absorption peaks which correspond to the frequencies of vibrations between the bonds of the atoms making up the material. Because each material is a unique combination of atoms, no two compounds produce the exact same infrared spectrum. Therefore, infrared spectroscopy can result in a positive identification (qualitative analysis) of every different kind of material. In addition, the size of the peaks in the spectrum is a direct indication of the amount of material present. With modern software algorithms, infrared is an excellent tool for quantitative analysis. The technique of Attenuated Total Reflectance (ATR) has in recent years revolutionised solid and liquid sample analyses because it combats the most challenging aspects of infrared analyses, namely sample preparation and spectral reproducibility. Within the context of this work Fourier transform infrared spectroscopy was carried out using the Attenuated Total Reflectance (ATR-FTIR) technique as this generated the best results for the study. ATR-FTIR spectroscopy was carried out on SBS, NIPAAm and SBS-g-NIPAAm copolymers as shown in Figure 11. The main bands for characterising the butadiene segment within SBS (Figure 11 (a)) are $\mathrm{CH}_{2}$ scissoring at 1449 $\mathrm{cm}^{-1}$, trans-1,4 C=C out of phase deformation at $964 \mathrm{~cm}^{-1},=\mathrm{CH}$ stretching at $3005 \mathrm{~cm}^{-1}$ and C$\mathrm{H}$ stretching at 2916 and $2844 \mathrm{~cm}^{-1}$. Regarding the PS segments, styrene absorption occurs at $697 \mathrm{~cm}^{-1}$, C-H out of plane deformation occurs at $3060 \mathrm{~cm}^{-1}$ and at $1601 \mathrm{~cm}^{-1}$ aromatic C-C stretching occurs (Munteanu \& Vasile, 2005; Romero-Sanchez et al., 2005a; Romero-Sanchez 
et al., 2005b). The ATR-FTIR spectrum for NIPAAm shown in Figure 11(b) illustrates bands corresponding to $\mathrm{C}=\mathrm{O}$ stretching and $\mathrm{NH}$ bending for secondary amides at $1655 \mathrm{~cm}^{-1}$ and $1544 \mathrm{~cm}^{-1}$. These bands are present as small shoulders in SBS-g-NIPAAm copolymer shown in Figure 11 (c). The peak at $1545 \mathrm{~cm}^{-1}$ for NIPAAm and SBS-g-NIPAAm copolymer was assigned as a symmetric deformation of $\mathrm{NH}_{3}{ }^{+}$. These results correspond to the finding of Erbil et al., (2004) and Ju et al.,(2002). However, the peaks present at $1617 \mathrm{~cm}^{-1}(C=C)$ and $1407 \mathrm{~cm}^{-1}(\mathrm{CH} 2=)$ in the NIPAAm spectrum disappeared for SBS-g-NIPAAm copolymer as illustrated in Figure 11(b). This suggests that NIPAAm had grafted to SBS resulting in the loss of the double bond associated with the monomer.

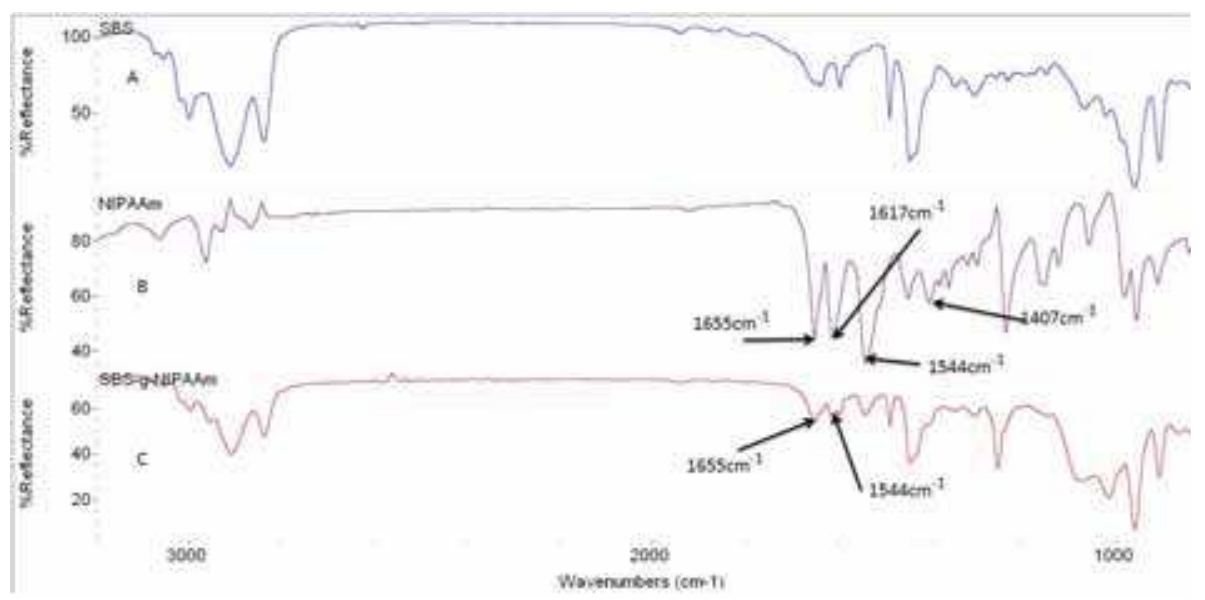

Fig. 11. Comparisons between the different ATR-FTIR spectrums where (a) is SBS (b) is NIPAAm and (c) is SBS-g-NIPAAm.

ATR-FTIR spectral analysis was used in conjunction with the DSC thermographs to analyse SBS-g-NVP copolymers. For illustrative purposes spectra containing non grafted NVP which polymerised to poly $N$-vinyl-2-pyrrolidinone (PVP), SBS-g-NVP using $2.5 \mathrm{~g}$ of NVP and SBS are shown in Figure 12. In the case of the PVP spectrum, Figure 12 (a), a broad $\mathrm{C}=\mathrm{O}$ stretching band was found at $1650 \mathrm{~cm}^{-1}$ which corresponds to results obtained by Devine \& Higginbotham (2003). Certain authors have found an absorption band for PVP at $1660 \mathrm{~cm}^{-1}$ and this is called amide I. This band is a combined mode with contributions of $\mathrm{C}=\mathrm{O}$ and C-N stretching (Muta et al., 2002; Cheryl \& Youngli, 2002). ATR-FTIR spectrum for the grafted sample depicted in Figure 12 (c) exhibited a peak at approximately $1664 \mathrm{~cm}^{-1}$, corresponding to the carbonyl group of PVP, which indicates monomeric growth of the grafted side chain. Szaraz et al.,(2000) has found that for pure liquid NVP two very strong bands occur in the IR spectrum. The band at $1629 \mathrm{~cm}^{-1}$, is a carbon-carbon double bond, corresponding to olefinic $\mathrm{C}=\mathrm{C}$ stretching which is usually found in the region of $1680-1630$ $\mathrm{cm}^{-1}$. The band at $1706 \mathrm{~cm}^{-1}$ is due to carbonyl stretching between $1750-1700 \mathrm{~cm}^{-1}$. However, as shown in the ATR-FTIR spectrum for grafted SBS-g-NVP copolymer, a small shoulder formed at $1714 \mathrm{~cm}^{-1}$ indicating that carbonyl stretching had occurred. This band is associated with un-reacted NVP as outlined by Szaraz et al., (2000) suggesting that NVP is still present within the grafted matrix, and so there is need to wash the samples after they have been fully synthesised. 


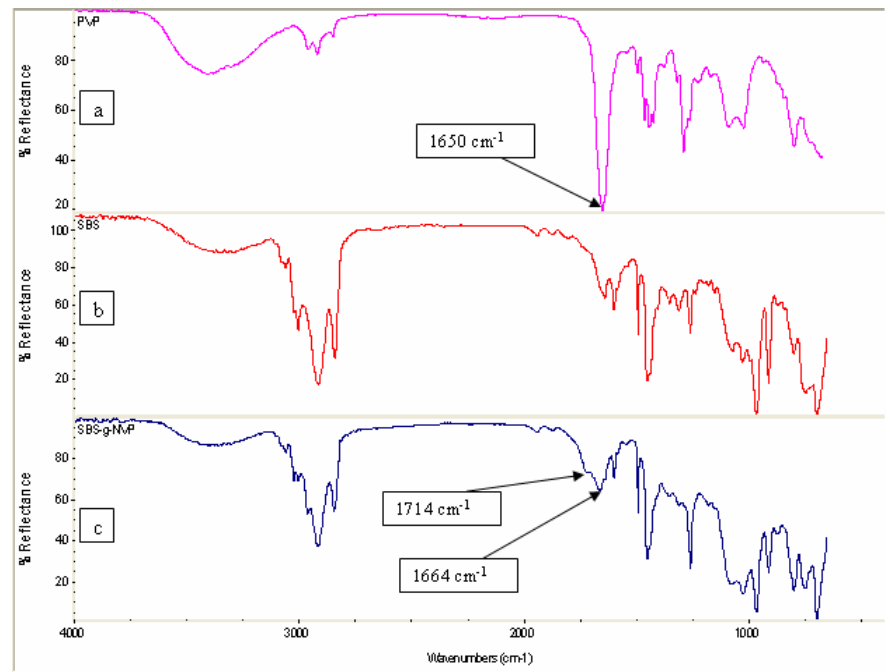

Fig. 12. Comparisons between the different ATR-FTIR spectra where (a) is PVP, (b) is SBS and (c) is SBS-g-NVP. (Kennedy \& Higginbotham, 2010)

\section{Topography of SBS and the grafted SBS coatings}

Improved compatibility is a desired feature for biomedical product such as a coating which comes in contact with blood during clinical use. The response of blood to a foreign material can be aggressive, resulting in surface-induced thrombus (clot) formation, which can impair or disable the function of the coating and most importantly threaten a patient's health. In light of the biomedical potential of SBS based copolymers it is important to have a firm understanding of the materials surface properties. In order to minimise interfacial problems between the host tissues and the fluids, a biomedical material must exhibit a specific surface chemical behaviour (Yang \& Tsai, 2010; Adamson, 1990; Andrade, 1985). All synthetic materials used in blood-contacting medical coatings promote surface-induced thrombotic phenomena to various extents. These events are initiated by non-specific protein adsorption followed by platelet adhesion, activation and aggregation on the biomaterial surface. The resulting thrombus can impair the function of the implanted devices, while thromboembolic events can occlude blood vessels leading to serious cardiovascular complications. Hence, non-thrombogenicity is a highly desired surface property for blood-contacting biomaterials. Thus, surface roughness is of significant interest in biomedical coatings because it is an important property which influences friction as well as wettability when in contact with a biological environment.

\subsection{White light profilometry}

One method of determining surface values of a material is to employ a technique known as White light profilometry which scans a surface using white light, thus providing surface structural analysis without using physical contact. The surfaces are characterised using amplitude parameters such as average surface roughness (Ra) or root mean square (RMS) roughness which can be summarised by a single "average roughness" value which is a close approximation of the arithmetic average roughness-height, calculated from the profile chart 
of the surface. The Ra value is the average deviation of all points, calculated using equation 1 , from a plane fit of the test surface. A graphic representation showing how Ra is conceived is illustrated in Figure 13.

$$
R_{a}=\frac{1}{L} \int_{0}^{L} z(x) d x
$$

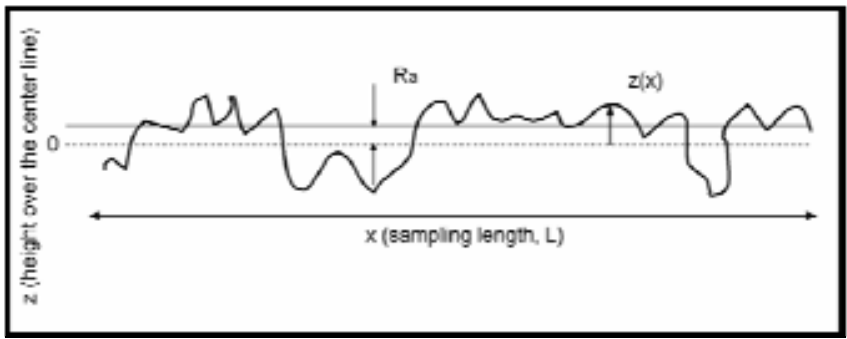

Fig. 13. Illustration of the average roughness, $\mathrm{Ra}$, where $\mathrm{z}(\mathrm{x})$ is the surface height in point $\mathrm{x}$ relative to a mean line and $\mathrm{L}$ is the overall length of the profile under examination.

The standard deviation of the profile heights, RMS, is a parameter calculated by the average of the square roots of all of the Ra values. This parameter is the most widely used and its numerical value is about $11 \%$ higher than the Ra value. This parameter is calculated using equation 2.

$$
R M S=\sqrt{\frac{1}{L} \int_{0}^{L} z(x)^{2} d x}
$$

The height of a selected material can be evaluated using Peak to Valley (PV) value which is the distance between the highest and lowest points within the sample. A graphical representation of how a PV value is determined is illustrated in Figure 14.

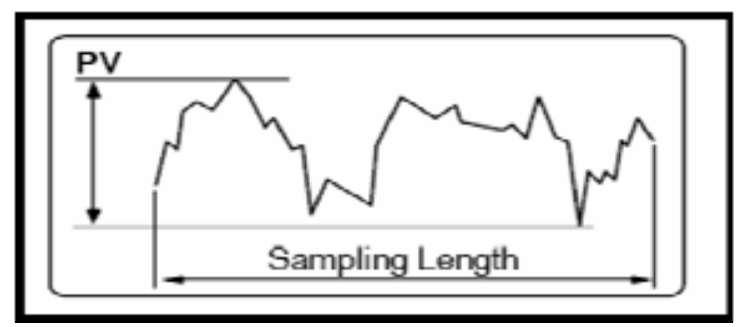

Fig. 14. Illustration of the peak to valley height (PV).

Kennedy et al.,(2010) used this technique to evaluate the roughness and height of SBS-gNIPAAm grafted copolymers. As illustrated in Figure 15, the root mean square (RMS), as well as Peak to Valley (PV) values were $0.128 \mu \mathrm{m}$ and $1.651 \mu \mathrm{m}$ respectively for the SBS copolymer. However, when these values were compared to a SBS-g-NIPAAm and SBS-g NVP copolymers as shown in Figures 16 and 17 respectively, the RMS parameter $(1.125 \mu \mathrm{m}$ for SBS-g-NIPAAm and $0.859 \mu \mathrm{m}$ for SBS-g-NVP) and the PV value $(13.878 \mu \mathrm{m}$ for SBS-g- 
NIPAAm and $6.896 \mu \mathrm{m}$ for SBS-g-NVP) were greater than that of SBS. It was found that the $\mathrm{PV}$ of each of the grafted copolymers tested was influenced by monomeric concentrations and the amount of chloroform (used to dissolve SBS) still present in the sample after UV polymerisation. This is an important property characteristic which directly affects the nonthrombogenic properties of the material within a specific biological environment i.e. the smoother the surface, the less likely that thrombosis will occur. However, this roughness may aid in the muco-adhesion properties of the material which is advantageous in biological environments such as arteries.

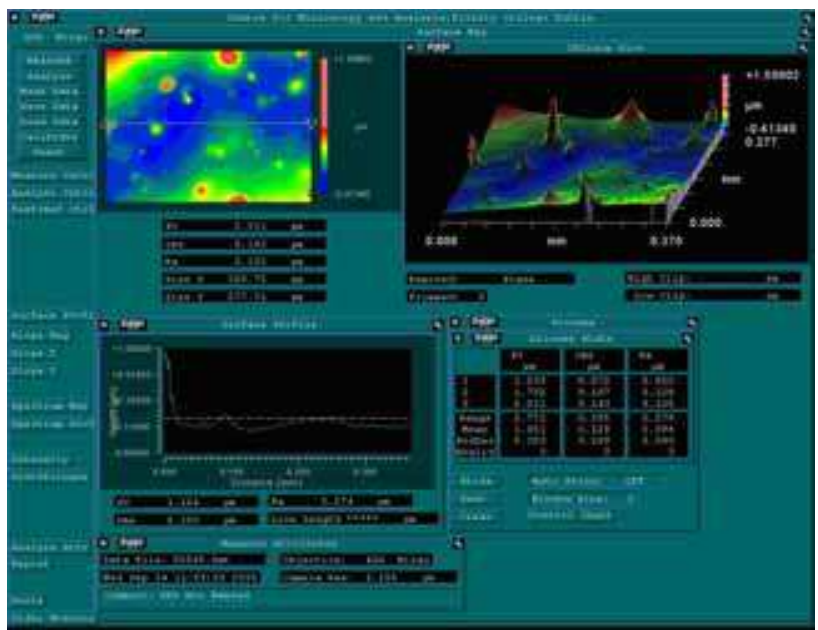

Fig. 15. A white light profilometry scan for a SBS copolymer illustrating 2D and 3D surface profiles as well as the PV value, $1.651 \mu \mathrm{m}$ and the RMS parameter, $0.128 \mu \mathrm{m}$.

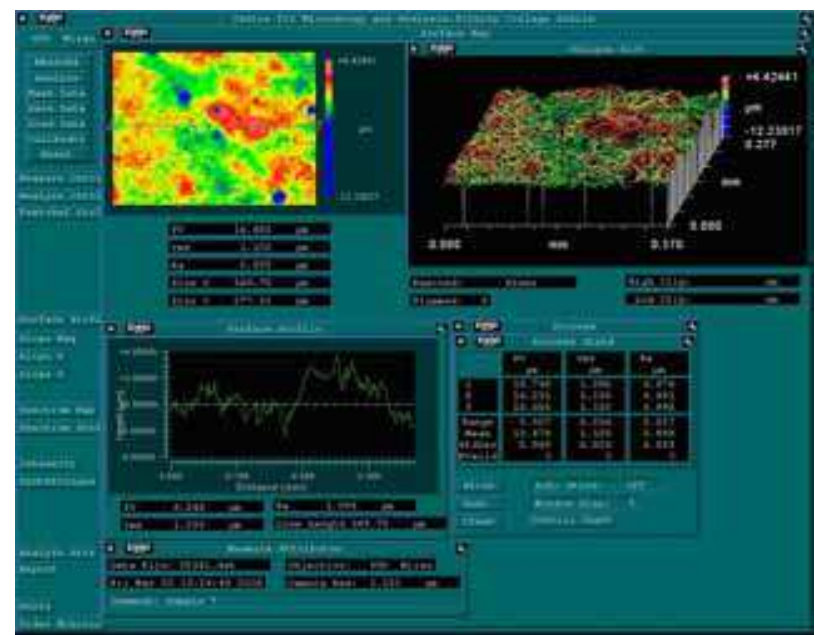

Fig. 16. A white light profilometry scan for a SBS-g-NIPAAm copolymer illustrating 2D and 3D surface profiles as well as the PV value, $13.878 \mu \mathrm{m}$ and the RMS parameter, $1.125 \mu \mathrm{m}$. 


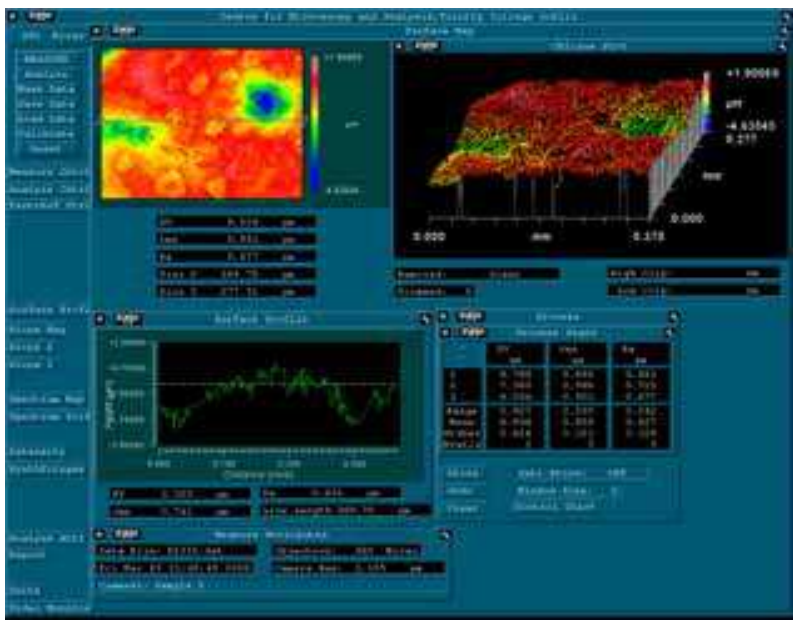

Fig. 17. A white light profilometry scan for a SBS-g-NVP coating illustrating 2D and 3D surface profiles as well as the PV value, $6.896 \mu \mathrm{m}$ and the RMS parameter, $0.859 \mu \mathrm{m}$.

\subsection{Scanning electron microscopy}

SEM micrographs of SBS, selected grafted polymers are illustrated in Figures 18 to 20.

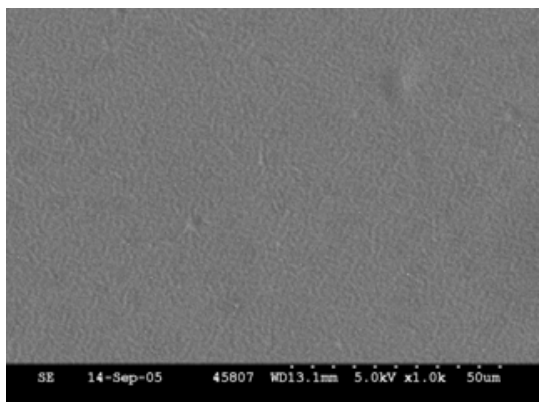

(a)

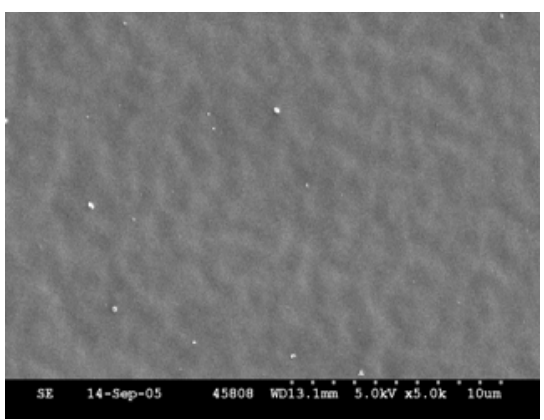

(b)

Fig. 18. SEM images of SBS at resolutions of $50 \mu \mathrm{m}$ (a) and $10 \mu \mathrm{m}(\mathrm{b})$. 
Mohammady et al., (2002) has confirmed that SBS, kraton D1101, exhibits a mixture of PS cylinders and lamellae embedded in the PB matrix when analysed by SEM. These findings correspond with observations made by the Authors, as shown in Figure 18, where SBS exhibits a uniform and dense structure with no pores present whereas the remaining grafted samples illustrated in Figures 19 and 20 revealed porous sponge like membranes due to the migration of chloroform during the UV polymerisation process.

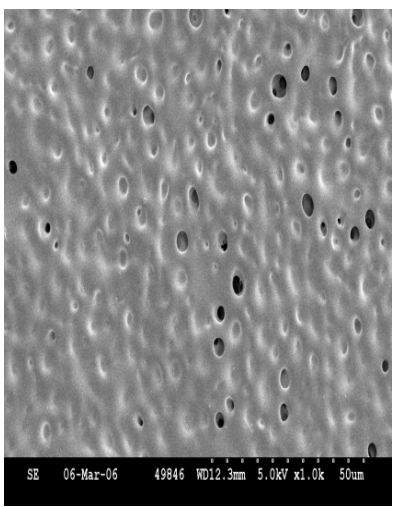

(a)

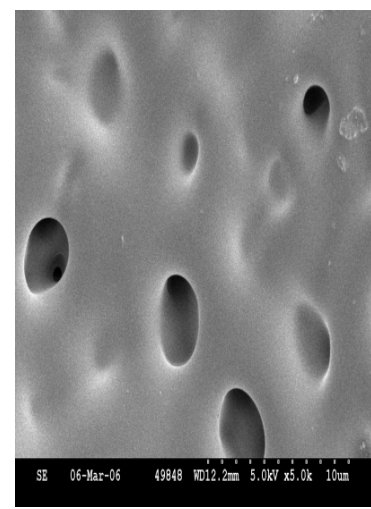

(b)

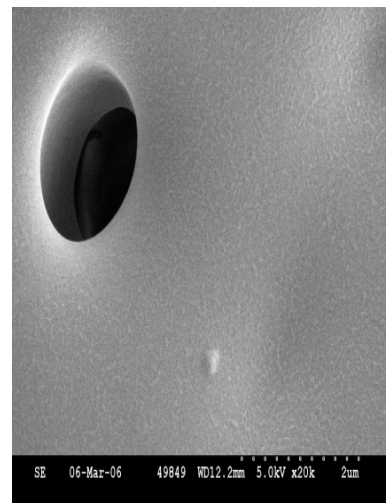

(c)

Fig. 19. SEM images of SBS-g-NIPAAm at resolutions of $50 \mu \mathrm{m}(\mathrm{a}), 10 \mu \mathrm{m}(\mathrm{b})$ and $2 \mu \mathrm{m}(\mathrm{b})$.

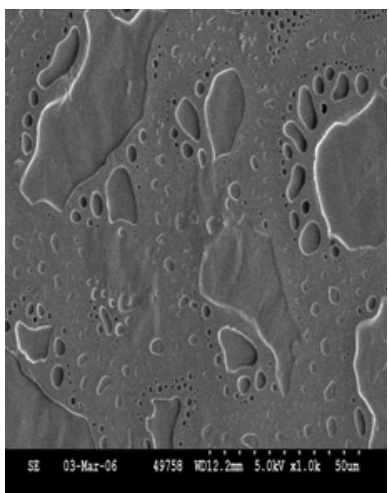

(a)

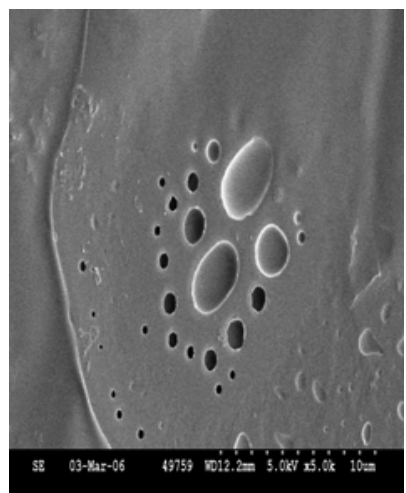

(b)

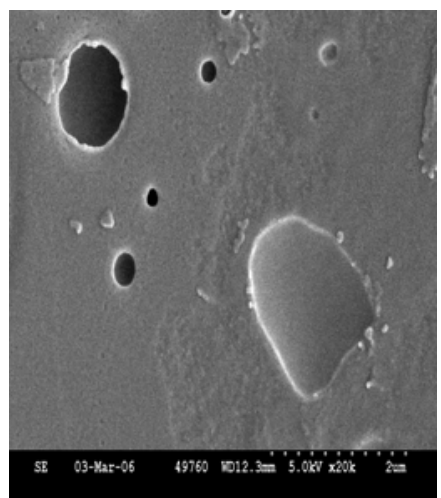

(c)

Fig. 20. SEM images of SBS-g-NVP at resolutions of $50 \mu \mathrm{m}$ (a), $10 \mu \mathrm{m}$ (b) and $2 \mu \mathrm{m}$ (c).

\subsection{Contact angle analysis of SBS and grafted SBS copolymers}

For the fabrication of biomedical coatings coming into contact with blood and tissue, it is usually desirable to create or utilise materials which exhibit high degrees of wettability. One technique used to predict wetting properties of biomedical polymers is the use of contact angles. When a droplet impacts onto a solid surface, a liquid film is formed which spreads out with a retarding velocity, due to the influence of both the surface tension and surface forces, resulting in the liquid film attaining a maximum spread when it comes to a stop. Young's law provides a relation between those forces outlined in equation 3. 


$$
\sigma_{l v} \cdot \cos \theta+\sigma_{l s}=\sigma_{s v}
$$

where $\theta$ is the angle of contact the liquid makes on the solid, $\sigma_{\mathrm{lv}}, \sigma_{\mathrm{ls}}$, and $\sigma_{\mathrm{sv}}$ represent the interfacial tensions at the boundaries between liquid (l), solid (s) and vapour (v).The contact angle, $\theta$, is usually referred as the wettability of a surface. The liquid is non-wetting when $90^{\circ}<\theta<180^{\circ}$ and wetting when $0^{\circ}<\theta<90^{\circ}$ (Moite \& Moreira, 2003). Wettability can be assessed directly using goniometry by measuring the angle formed between a solid surface and the tangent to the drop surface. A graphic illustrating the concept of wettability is shown in Figure 21.
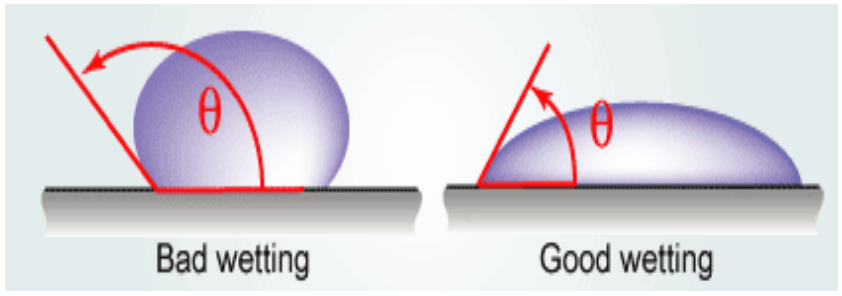

Fig. 21. A graphical representation of wettability.

Therefore, wettability is often referred to as hydrophilicity and is considered to be a surface property of a material as opposed to true hydrophilicity, which is considered to be a bulk property. A caveat to this design criterion is the fact that polymers are generally hydrophobic in nature due to their generally low surface tensions, resulting in polymers exhibiting poor wettability. For visual purposes, to illustrate principles of wettability, a digital goniometer was used and the results are illustrated in Figure 22, these images best demonstrate the affect of wettability on SBS as well as grafted SBS copolymers.

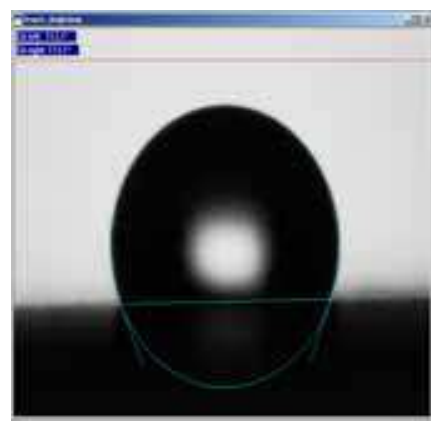

(a) $113^{\circ}$

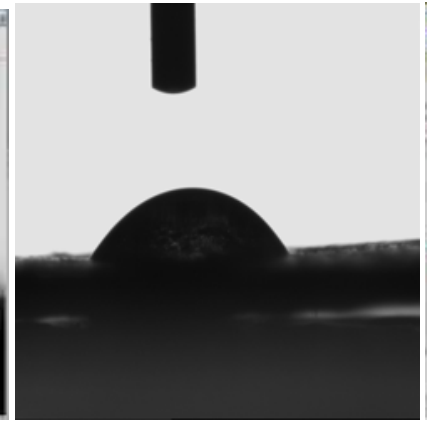

(b) $52^{\circ}$

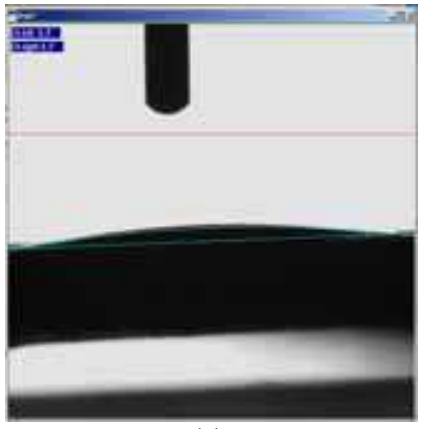

(c) $6^{\circ}$

Fig. 22. Contact angles representing the copolymers, where (a) SBS, (b) SBS-g-NIPAAm and (c) SBS-g-NVP.

From the images obtained the modification in the surface chemistry and wettability is reflected by the dramatic reduction in the contact angles as shown in Figures 22. Lassalle et al.,(2004) has found a contact angle of $95^{\circ}$ when $1 \%$ of $\mathrm{N}$-carbamyl maleamic acid was grafted onto SBS. Whereas, Yang et al.,( Yang 7Hsiue, 1996; Yang et al., 1997; Yang et al., 1998) reported similar trends when vinyl pyridine was grafted onto SBS and when dimethyl amino ethyl methacrylate was grafted onto SBS, contact angles of $77^{\circ}$ and $76^{\circ}$ were obtained. 
Therefore, by grafting a hydrophilic monomer/polymer onto a hydrophobic backbone the wettability of the material is increase. It is important to note, that the samples tested where not washed and the low contact angle for the SBS-g-NVP copolymer was in part due to the migration on polymerised poly $N$ - vinyl-2-pyrrolidone which is an excellent hydrophilic hydrogel, but the principle still applies whereby a hydrophobic material such as SBS can be made into a hydrophilic compound via grafting technologies.

\section{Conclusion}

Polymer science is by nature an interdisciplinary field, where it has found refuge in the traditional domains of engineering, chemistry and physics. However, the importance of this branch of science has now expanded and by the further integration of other disciplines such as biology, medicine and computing, new innovations have emerged resulting in opportunities which very much find itself in the fields of biomaterials. This chapter looked at such possibilities, where the tradition SBS copolymer (a thermoplastic elastomer) was modified into a grafted copolymer utilising hydrogel technology to create a potential medical application in the area of biomedical coatings.

To truly appreciate the breath and depth of the opportunities one must have a detailed understanding of the fundamental principles which occur within the materials such as phase separation, the domain theory, topography and reaction kinetics to name but a few. Only then can new materials be commercialised which capture the needs society has place on them.

\section{References}

Adamson, A.W. (1990).Physical Chemistry of Surfaces, Wiley, ISBN-13: 978-0471610199, New York,

Adhikari, R; Michler, GH; Godehardt,R; Ivan'kova EM.(2003). Deformation behaviour of styrene butadiene star block copolymer/hPS blend: influence of morphology. Polymer, Vol., 44, No., 26 (December 2003) pp 8041-8051, ISSN 0032-3861

Adhikari, R; Michler, GH; Knott, RB.(2004). Morphology and micromechanical behaviour of binary blends comprising block copolymers having different architectures. Polymer, Vol., 45, No., 1(January 2004) pp 241-246, ISSN 0032-3861

Andrade, J.D.(1985). Surface and Interfacial Aspects of Biomedical Polymers: Surface Chemistry and Physics Vol. 1, Plenum Publications, ISBN-13: 978-0306417412, New York.

Brydson, J.A.(1978) Rubber Chemistry, Applied Science Publishers, ISBN-13: 978-0853344360, London.

Burford, RP; Markotsis, MG; Knott, RB.(2003) Small angle neutron scattering and transmission electron microscopy studies of interpenetrating polymer networks from thermoplastic elastomers. Nuclear Instruments and Methods in Physics Research Section B: Beam Interactions with Materials and Atoms, Vol.208, pp 58-65, ISSN 0168583X

Cheryl, L; Youngli, M.(2002). A study of blending and complexation of poly(acrylic acid)/poly(vinyl pyrrolidone). Polymer, Vol. 43.., No. 3, (February 2002) pp 823829, ISSN : 0032-3861

De Sarkar, M; De, PP; Bhowmick, AK.(1999). Influence of hydrogenation and styrene content on the unaged and aged properties of styrene-butadiene copolymers. $\mathscr{C}$ Material Science, Vol. 34, No.8(April 1999), pp 1741-1747, ISSN 0022-2461 
Devine D.M; Higginbotham C.L.(2003). The synthesis of a physically crosslinked NVP based hydrogel. Polymer, Vol. 44, No.26 (December 2003 ), pp7851-7860, ISSN 0032-3861.

Durne, KV; Mele, B; Loos, W; Du Prez, F.(2005). Introduction of silica into thermo-responsive poly(N-isopropylacrylamide) hydrogels. A novel approach to improve response rates. Polymer, Vol. 46, No.23 (November 2005), pp 9851-9862, ISSN 0032-3861

Erbil, C; Kazancioglu, E; Uyanik, N.(2004). Synthesis, characterisation and thermoreversible behaviours of poly (dimethylsiloxane)/ poly(N-isopropylacylamide) semi interpenetrating network, European Polymer eburnal, Vol. 40, No.6 (June 2004), pp 1145-1154, ISSN 00143057.

Escobar-Barrios,VA; Najera,RH; Petit,A ; Pla, F.(2003). Selective hydrogenation of butadiene styrene copolymers using a Ziegler-Natta type catalyst 2. Thermal properties European Polymer Journal, Vol. 39,No.6 (June 2003), pp 1151-1167, ISSN 0014-3057

Geever, L.M.; Cooney, C.C; Lyons, J.G; Kennedy, J.E; Nugent, M. J.D; Devery,S; Higginbotham, C.L.(2008). Characterisation and controlled drug release from novel drug-loaded hydrogels, European eburnal of Pharmaceutics and Biopharmaceutics, Vol. 69, No.3 (August 2008), pp 1147-1159, ISSN 0939-6411.

Geever, L.M; Devine, D.M; Nugent, M. J.D; Kennedy, J.E; Lyons, J.G; Hanley, A; Higginbotham, C.L.(2006). Lower critical solution temperature control and swelling behaviour of physically crosslinked thermosensitive copolymers based on N-isopropylacrylamide, European Polymer eburnal, Vol. 42, No.10 (October 2006), pp 2540-2548, ISSN 0014-3057.

Geever, L.M; Mínguez, C, M; Devine, D.M; Nugent, M. J.D; Kennedy, J.E; Lyons, J.G; Hanley, A; Devery, S; Tomkins, P.T; Higginbotham, C.L.(2007). The synthesis, swelling behaviour and rheological properties of chemically crosslinked thermosensitive copolymers based on N-isopropylacrylamide, eburnal of Materials Science, 2007 Vol. 42, No.12 (March 2007), pp 4136-4148, ISSN : 0022-2461.

Gruver, J.T; Kraus, G.(1964). J.Appl.Polym.Sci. Pt A 2, pp 797, cited in Holden, G; Kricheldorf H.R; Quirk R.P Editors(2004). Thermoplastic Elastomers, Hanser, ISBN 9783446223752, Munich.

Hirata, I.(2004). Simple method for preparation of ultra-thin poly(N-isopropylacrylamide) hydrogel layers and characterization of their thermo-responsive properties, Polymer, Vol. 45, No.16 (July 2004), pp 5569-5578, ISSN 0032-3861.

Holden G. J. (1965) Appl. Polym. Sci. Vol 9, pp 2911, cited in Holden, G; Kricheldorf H.R; Quirk R.P Editors(2004). Thermoplastic Elastomers, Hanser, ISBN 9783446223752, Munich.

Holden, G; Kricheldorf H.R; Quirk R.P Editors(2004). Thermoplastic Elastomers, Hanser, ISBN 9783446223752, Munich.

Holden, G; Hansen, D.R. (2004). Styrenic Thermoplastic Elastomers. pp 45-65. In: Holden, G; Kricheldorf H.R; Quirk R.P Editors(2004). Thermoplastic Elastomers, Hanser, ISBN 9783446223752, Munich.

Holden, G; Milkovich,R.(1962) (to shell oil co), U.S. Patent 3,265,765, filed January 1962.

Huang, NJ; Sundberg, DC. (1995 a). Fundamental Studies of Grafting Reactions in Free Radical Copolymerisation. 1. A Detailed kinetic Model for Solution Polymerisation. Journal of Polymer Science Part A, Polymer Chemistry, Vol. 33, No.15 (November 1995), pp 2533-2550, ISSN 0887-624X.

Huang, NJ; Sundberg, DC. Fundamental Studies of Grafting Reactions in Free Radical Copolymerisation.2.(1995b). Grafting of Styrene, Acrylate, and Methacrylate Monomers onto cis-Polybutadiene Using AIBN Initiator in Solution 
Polymerisation. Journal of Polymer Science Part A: Polymer Chemistry, Vol. 33, No.15 (November 1995), pp 2551-2570, ISSN 0887-624X.

Huang, NJ; Sundberg, DC.(1995 c). Fundamental Studies of Grafting Reactions in Free Radical Copolymerisation.3. Grafting of Styrene, Acrylate, and Methacrylate Monomers onto cis-Polybutadiene Using Benzoyl Peroxide Initiator in Solution Polymerisation. Journal of Polymer Science Part A, Polymer Chemistry, Vol. 33,No.15 (November 1995), pp 2571-2586, , ISSN 0887-624X.

Huang, NJ; Sundberg, DC.(1995 d). Fundamental Studies of Grafting Reactions in Free Radical Copolymerisation.4. Grafting of Styrene, Acrylate, and Methacrylate Monomers onto vinyl-polybutadiene using benzoyl peroxide and AIBN Initiators in Solution Polymerisation. Journal of Polymer Science Part A, Polymer Chemistry, Vol. 33,No.15 (November 1995), pp 2587-2603, ISSN 0887-624X.

Jiang, DD; Wilkie, CA.(1998). Graft copolymerisation of Methacrylic acid, Acrylic acid and Methyl acrylate onto Styrene- butadiene Block copolymers. Eur. Polym. eburnal, Vol. 34, No.7 (July 1998), pp997-1006, ISSN 0014-3057.

Ju, H.K; Kim, S.Y; Kim, S.J; Lee ,Y.M.(2002). pH/Temperature responsive semi-IPN hydrogels composed of alginate and poly(N-isopropylacrylamide), JAppl Polym Sci. Vol. 83, No. 5(January 2002), pp 1128-1139, ISSN 0021-8995.

Kennedy, J.E; Devine, D.M; Lyons J.G; Geever, L.M; Higginbotham, C. L.(2009). The synthesis and characterisation of grafted random styrene butadiene for biomedical applications. eburnal of Materials Science, Vol. 44., No. 3(February 2009) pp 889-896, ISSN 1573-4803.

Kennedy, JE; Higginbotham, CL.(2010). Synthesis and characterisation of styrene butadiene styrene-g-N-isopropylacrylamide via UV polymerisation for potential use in biomedical applications, eburnal of Materials Science, Vol. 45, No. 3 (February 2010), pp 599-606, ISSN 0022-2461.

Kennedy, JE; Higginbotham, CL.(2010) Synthesis and characterisation of styrene butadiene styrene-g-N vinyl -2-pyrrolidinone for use in biomedical applications, Materials Science and Engineering $C$, doi:10.1016/j.msec.2010.09.004

Kennedy, JE; Lyons, JG; Geever, LM; Higginbotham, CL.(2009) Synthesis and characterisation of styrene butadiene styrene-g-acrylic acid for potential use in biomedical applications, Materials Science and Engineering $C$, Vol. 29, No.5 (June 2009), pp 1655-1661, ISSN 0928-4931

Kim, J. K; Kim, W. H; Lee, D. H.(2002). Adhesion properties of UV crosslinked polystyreneblock-polybutadiene-polystyrene copolymer and tackifier mixture. Polymer, Vol. 43, No.18 (August 2002), pp 5005-5010, ISSN 0032-3861.

Knoll, K; Niessner, N.(1998). Styrolux+ and styroflex+ : From transparent high impact polystyrene to new thermoplastic elastomers syntheses, applications and blends with other styrene based polymers. Proceedings of Macromol. Symp, pp 231-243, ISBN 3-527-29800-2, Paris, 7-11 July, 1997, Wiley-VCH, Switzerland

Lasalle, V.L; Failla, M.D; Valles, E.M; Martin-Martinez, JM.(2004). Chemical modification of styrene-butadiene-styrene co-polymer by grafting of N- carbamyl maleamic acid, $J$ Adhesion Sci. Technol, Vol. 18, No. (15-16), pp1849-1860, ISSN 0169-4243.

Lee, W; Chen, Y. Graft copolymerisation of N-isopropylacrylamide on styrene-butadienestyrene block copolymer.(2001). eburnal of Applied Polymer Science, Vol. 82, No.11 (December 2001), pp 2641-2650, ISSN 0021-8995. 
Madhusudhan, RB; Raghunath, RP.(1999). Grafting of maleic anhydride onto acrylonitrilebutadiene-styrene ter-polymer: synthesis and characterization. Polym Plast Technol Eng, Vol. 38, No.5 (November 1999), pp 967-977, ISSN 0360-2559.

Mateo, JK; Bosch, P; Serrano, J; Calvo, M.(2000). Sorption and diffusion of organic solvents through photo crosslinked SBS block copolymers, European Polymer eburnal, Vol. 36, No.9 (September 2000), pp 1903-1910, ISSN 0014-3057.

Minoura, F.N., Soft tissue compatible polymers.(1993) In: Biomedical Applications of Polymeric Materials, Tsuruta, T; Hayashi, T; Kataoka, K; Ishihara, K; Kimura, Y. Editors, p. 118. CRC Press, ISBN-13: 9780849345197, Boca Raton, FL,

Mohammady, S.Z; Mansour, A.A; Knoll, K; Stoll, B.(2002). Detection of the glass relaxation process of the PS- phase in block copolymers. Polymer, Vol. 43, No. 8(April 2002), pp 2467-2478, ISSN 0032-3861.

Mohammady, S.Z; Mansour, A.A; Stoll.B.(2001). Dynamic Mechanical Relaxation Behaviour of Block Copolymers at High temperatures. eburnal of Polymer Science Part B: Polymer Physics, Vol. 39, No.18 (September 2001), pp 2198-2206, ISSN 0887-6266

Moita, A. S. H; Moreira, A. L. N.(2003). Influence of Surface Properties on the Dynamic Behaviour of Impacting Droplets. 9th International Conference on Liquid Atomization and Spray Systems

Mrrov ,Z ; Velichkova, R.(1993). Modification of styrene-isoprene block copolymer-3. Addition of maleic anhydride-mechanism. Eur Polym eburnal, Vol.29, No. 4(April 1993), pp 597-601, ISSN 0014-3057.

Munteanu, SB; Vasile, C.(2005). Thermal and thermo-oxidative behaviour of butadienestyrene copolymer with different architectures. Polymer Degradation and Stability, Vol .89, No.3, (September 2005) pp 501-512, ISSN 0141-3910.

Murata, H; Chang, B. J; Prucker, O; Dahm, M; Ruhea, J.(2004). Polymeric coatings for biomedical devices. Surface Science, Vol. 570, No.1-2 (October 2004), pp 111-118, ISSN 0039-6028

Muta, H; Ishida, K; Tamaki, E; Satoh, M.(2002). An IR study on ion-specific and solventspecific swelling of poly(N-vinyl-2-pyrrolidone) gel. Polymer, Vol. 43, No.1 (January 2002), pp 103-110, ISSN 0032-3861

Nestle, H; Heckmann,W; Steininger,H; Knoll,K.(2007). Towards quantification of butadiene content in styrene-butadiene block copolymers and their blends with general purpose polystyrene (GPPS) and the relation between mechanical properties and NMR relaxation times. Analytica chimica acta, Vol. 604, No.1 (November 2007), pp 54-61, ISSN 0003-2670.

Rohr, T; Ogletree, D. F; Svec, F; Frechet, J. M .J.(2003). Surface Functionalisation of Thermoplastic Polymer for the Fabrication of Microfluidic Devices by Photoinitiated Grafting. Adv. Funct. Material, Vol. 13, No.4(April 2003), pp 264-270.

Romero-Sánchez, MD; Pastor-Blas, MM; Martín-Martínez, JM. (2005a). Environmental friendly surface treatments of styrene-butadiene-styrene rubber: Alternative to the solvent-based halogenation treatment. International eburnal of Adhesion and Adhesives, Vol. 25, No.1 (February 2005), pp 19-29, ISSN 0143-7496

Romero-Sánchez, MD; Pastor-Blas, MM; Martín-Martínez, JM; Walzak, MJ. (2005b) Addition of ozone in the UV radiation treatment of a synthetic styrene-butadiene-styrene (SBS) rubber. International eburnal of Adhesion and Adhesives, Vol. 25, No.4 (August), pp 358-370, ISSN 0143-7496 
Sheng, J; Lu, XL Yao, KD. (1990). Investigation of graft polymerization of maleic anhydride onto polybutadiene rubber. el Macromol Sci-Chem, Vol. 27, No.2 (February 1990), pp 167-178, ISSN 0022-233X.

Spaans, RD; Muhammad, M; Williams, MC.(1999). Probing the interfacial region of microphase separated block copolymers by differential scanning calorimetry. eburnal of Polymer Science Part B: Polymer physics, Vol. 37, No. 4(February 1999), pp 267-274,

Spaans, RD; Williams, MC.( 1995). Non linear Viscoelasticity of ABA Block copolymers Melts: Stress Relaxation and Recovery. Ind. Eng. Chem. Res. Vol. 34, No.10 (October 1995), pp 3496-3507, ISSN 0888-5885.

Szaraz, L; Forsling, W.(2000). A Spectroscopic study of the solvation of 1-vinyl-2pyrrolidone and poly(1-vinyl-2-pyrrolidone) in different solvents. Polymer, Vol. 41, No.13 (June 2000), pp 4831-4839, ISSN 0032-3861.

Szwarc, M. Nature. (1956) Vol. 178, pp 1168-1169. cited in Holden, G; Kricheldorf H.R; Quirk R.P Editors (2004). Thermoplastic Elastomers, Hanser, ISBN 9783446223752, Munich.

Szwarc, M; Levy,M; Milkovich, R. J. (1956). Am. Chem. Soc. Vol.78, pp 2656- 2657. cited in Holden, G; Kricheldorf H.R; Quirk R.P Editors(2004).Thermoplastic Elastomers, Hanser, ISBN 9783446223752, Munich.

Van der Vegt, A.K. (2005) From polymers to plastics. Delf University press Netherlands:

Wagner D.(2004), Kunststoffe Plast Europe 6/2004, available online from www.kunststoffe.de/peusing using DOI: PE102911

Xiang, ZC; Qinghua, L; Jie, Y. (2001). Photochemical surface modification of polyinide containing benzophenone unit by UV light source. Chemistrymag.org. Vol. 3, No.11 (November2001)pp54-60.Available from http://www.mdpi.org/cji/cji/2001/03b054pe.htm

Yang, JM; Hsiue, GH. (1996). Radiation-induced graft copolymer SBS-g-VP for biomaterial usage. eburnal of Biomaterials Materials Research, Vol 31, No.2 (June 1996) pp 281-286, ISSN 0021-9304.

Yang, JM; Jong, YJ; Hsu, KY. Hsu; Chang, CH.(1998). Preparation and characterisation of heparin-containing SBS-G-DMAEMA copolymer membrane. J Biomed. Mater Research, Vol. 39, No.1(January 1998) pp 86-91, ISSN 0021-9304.

Yang, JM; Jong, YJ; Hsu, KY.(1997). Preparation and properties of SBS -G-DMAEMA copolymer membrane by ultraviolet radiation. eburnal of Biomaterials Materials Research, Vol. 35, No. 2(May 1997) pp 175-180, ISSN 0021-9304.

Yang, JM; Tsai, SC. (2010). Biocompatibility of epoxidized styrene-butadiene-styrene block copolymer membrane. Materials Science and Engineering: C, 2010 doi:10.1016/j.msec.2010.06.014]

Zhang, A ; Li,C. (2003). Chemical initiation mechanism of maleic anhydride grafted onto styrene-butadiene-styrene block copolymer. European Polymer burnal, Vol. 39, No.6 (June 2003) pp 1291-1295, ISSN 0014-3057.

Zhang, X; Lewis, P; Chu, C.(2005). Fabrication and characterization of a smart drug delivery system: microsphere in hydrogel. Biomaterials, Vol. 26, No.16 (June 2005) pp 32993309, ISSN 0142-9612 


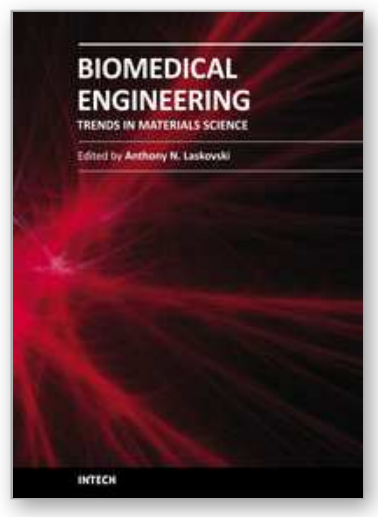

\author{
Biomedical Engineering, Trends in Materials Science \\ Edited by Mr Anthony Laskovski
}

ISBN 978-953-307-513-6

Hard cover, 564 pages

Publisher InTech

Published online 08, January, 2011

Published in print edition January, 2011

Rapid technological developments in the last century have brought the field of biomedical engineering into a totally new realm. Breakthroughs in materials science, imaging, electronics and, more recently, the information age have improved our understanding of the human body. As a result, the field of biomedical engineering is thriving, with innovations that aim to improve the quality and reduce the cost of medical care. This book is the second in a series of three that will present recent trends in biomedical engineering, with a particular focus on materials science in biomedical engineering, including developments in alloys, nanomaterials and polymer technologies.

\title{
How to reference
}

In order to correctly reference this scholarly work, feel free to copy and paste the following:

James E. Kennedy and Clement L. Higginbotham (2011). Synthesis and Characterisation of Styrene Butadiene Styrene Based Grafted Copolymers for Use in Potential Biomedical Applications, Biomedical Engineering, Trends in Materials Science, Mr Anthony Laskovski (Ed.), ISBN: 978-953-307-513-6, InTech, Available from: http://www.intechopen.com/books/biomedical-engineering-trends-in-materials-science/synthesis-andcharacterisation-of-styrene-butadiene-styrene-based-grafted-copolymers-for-use-in-pote

\section{INTECH}

open science | open minds

\section{InTech Europe}

University Campus STeP Ri

Slavka Krautzeka 83/A

51000 Rijeka, Croatia

Phone: +385 (51) 770447

Fax: +385 (51) 686166

www.intechopen.com

\section{InTech China}

Unit 405, Office Block, Hotel Equatorial Shanghai

No.65, Yan An Road (West), Shanghai, 200040, China

中国上海市延安西路65号上海国际贵都大饭店办公楼405单元

Phone: +86-21-62489820

Fax: +86-21-62489821 
(C) 2011 The Author(s). Licensee IntechOpen. This chapter is distributed under the terms of the Creative Commons Attribution-NonCommercialShareAlike-3.0 License, which permits use, distribution and reproduction for non-commercial purposes, provided the original is properly cited and derivative works building on this content are distributed under the same license. 